\title{
Editorial: Advances in Pollutant Transport in Critical Zone Environments
}

\author{
Huilian Ma ${ }^{1 *}$, Yusong $\mathrm{Li}^{2}$, Chongyang Shen ${ }^{3}$, Constantinos V. Chrysikopoulos ${ }^{4}$ and \\ Hyunjung Kim $^{5}$
}

${ }^{1}$ Department of Geology and Geophysics, University of Utah, Salt Lake City, UT, United States, ${ }^{2}$ Department of Civil and Environmental Engineering, University of Nebraska-Lincoln, Lincoln, NE, United States, ${ }^{3}$ Department of Soil and Water Sciences, China Agricultural University, Beijing, China, ${ }^{4}$ School of Environmental Engineering, Technical University of Crete, Chania, Greece, ${ }^{5}$ Department of Mineral Resources and Energy Engineering, Jeonbuk National University, Jeonju, South Korea

Keywords: contaminant transport, riverbank filtration, particle shape, granular media, vadose zone monitoring, groundwater pollution

\section{Editorial on the Research Topic}

\section{Advances in Pollutant Transport in Critical Zone Environments}

One major environmental challenge facing humankind is the constantly increasing pollution of water and soil resources on a global scale. The substances that cause such pollution arise primarily from human-made wastes, including agricultural and industrial wastes, household garbage, oil spills, and other toxic materials. The spatiotemporal distribution of these polluting substances in soil and water systems is determined by an interplay of many factors such as physicochemical properties of pollutants, soil grain properties and structure, fluid flow chemistry and velocity, biological activity, and other environmental factors (temperature, precipitation). In this issue, we

\section{OPEN ACCESS}

Edited and reviewed by:

Carl I. Steefel,

Lawrence Berkeley National Laboratory, United States

${ }^{*}$ Correspondence:

Huilian Ma

huilian.ma@utah.edu

Specialty section:

This article was submitted to

Water and Critical Zone,

a section of the journal

Frontiers in Water

Received: 09 April 2021

Accepted: 03 May 2021

Published: 28 May 2021

Citation:

Ma H, Li Y, Shen C,

Chrysikopoulos CV and Kim H (2021)

Editorial: Advances in Pollutant

Transport in Critical Zone

Environments. Front. Water 3:693102.

doi: 10.3389/frwa.2021.693102 have collected a series of articles that advance our fundamental understanding of the transport of solute and colloidal pollutants, their spread in Critical Zone environments, and recent monitoring and control efforts. These articles address the issue from various perspectives, spanning pore-scale, continuum-scale, and field studies in saturated groundwater and vadose zones.

Water and soil resources are valuable but finite. Their loss and degradation may not be recoverable within a human lifetime, especially when pollutants do not breakdown and tend to be persistent in the environment. As revealed in a case study from a historical fire training site in New South Wales, Australia (Bekele et al.), despite that the source of contaminants (e.g., aqueous film forming foam for firefighting) was stopped about 20 years ago, the contaminants themselves (i.e., PFAS-perfluoroalkyl and polyfluoroalkyl substances) can remain in and around the site with considerably high concentration, posting as ongoing sources for contamination to groundwater systems for years to come. The fate and transport of PFAS are found to correlate greatly with soil geochemical properties (e.g., soil type, $\mathrm{pH}$ ) as they migrate in the vadose zone toward the groundwater table. As these synthetic PFAS have been widely used in many industries (including coating, food packaging, cleaning products, fire-fighting foams), the threat these materials pose to the environment and humans cannot be exaggerated.

Agrochemicals (e.g., fertilizers, herbicides, pesticides) have been extensively used to meet the increasing demand for food, despite the proven toxicity of some of them. For instance, bipyridinium herbicides (e.g., Paraquat and Diquat) are still very popular in many developing countries due to their low cost. While killing "weeds," the herbicides inevitably interact with the soil. An experimental study shows that these two herbicides may not significantly adsorb to natural sandy soil but are highly adsorbable to clay and natural organic matter (Tadeo-Jalife et al.). Poor adsorption of toxic agrochemicals onto sandy soil may cause leaching into aquifers, directly 
contaminating groundwater or surface water resources. On the other hand, high binding affinities of the toxic materials for clay soil matrix components not only render the polluted soil unusable, but indirectly contribute to groundwater pollution owing to perturbation and remobilization of natural soil particles, changes in water chemistry (e.g., $\mathrm{pH}$, ionic strength) and aquifer hydraulics caused by rainfall or fractures.

In addition to the aforementioned molecular pollutants, colloidal pollutants such as pathogenic viruses and bacteria widely exist in the subsurface. Colloidal particles may also play the role of a carrier to enhance the transport of molecular pollutants. Our current understanding of colloid transport in soil and water systems is largely based on the "homogeneous spheres" assumption for colloidal particles. However, most particulate contaminants in the environment exist in non-spherical shapes and with varied surface properties. The non-spherical shape (e.g., rod-like) causes the contaminants to exhibit distinct rotation and translation behaviors relative to spheres, as demonstrated in a numerical modeling study ( $\mathrm{Li}$ and $\mathrm{Ma}$ ). Compared to spheres, the rod-shaped particulates of $\sim 0.4-2 \mu \mathrm{m}$ size range are shown to have higher deposition (about a factor of 2-10) and travel farther downstream in simple groundwater flow channels under favorable deposition conditions. Therefore, particle shape is an important factor that could greatly influence contaminant transport and migration in groundwater and soil systems.

The pollutants examined in the aforementioned studies may eventually transport through the soil and enter into groundwater. Indeed, groundwater pollution mainly originates on the land surface, such as soil. Once groundwater resources are contaminated, their remediation has proven to be very challenging. However, most groundwater pollution monitoring programs are based on observation wells that penetrate the saturated section of the subsurface and reach the groundwater table. Therefore, the identification of pollution in well water clearly indicates that the groundwater has already been polluted. To achieve early warnings of pollution tendency, obtaining realtime information on the hydraulic and chemical states of the unsaturated zone (i.e., vadose zone) is essential. This is a serious paradoxical situation we currently stand facing. As such, the need for an urgent call to shift our focus of pollution monitoring from groundwater itself to the unsaturated zone is discussed (Dahan).

Pollution monitoring, together with pollution control and remediation techniques, is critical to prevent the groundwater from being contaminated by pollutants from land surfaces. This issue includes a field study of pollution control near a mining-impacted alluvial floodplain site in Rio Nambija, Ecuador (Johnson et al.). Based on a filtration-driven deposition principle, this work demonstrates that a forced lateral flow channel constructed using gravel was able to facilitate removal of particlebound metal contaminants (e.g., lead, mercury, iron), and recover precious gold simultaneously. A pilot system of multiple lateral channels is to be implemented in 2021. If successful, this strategy can be applied to other mining-impacted streams to achieve hydraulic, water quality and economic (precious metal mining) objectives at a relatively low cost. In many developing countries, small-scale mining wastes are often disposed directly into adjacent rivers/streams due to lack of resources or extreme seasonal flooding, which dramatically damages surface water and groundwater quality. This treatment technique holds great potential in those countries.

Our valuable soil and water resources are gravely polluted by humans' activities, either accidentally or intentionally. Various factors of pollutant-water-soil systems complicatedly impact transport and spread of pollutants in Critical Zone environments. Restoring and maintaining environmental sustainability require a thorough understanding of the mechanisms controlling pollutant fate and transport, effective and unrelenting monitoring, and intervention and remediation measures. Moreover, it is imperative to tackle pollution problems from the root, significantly reducing human-made wastes. This calls for efforts to raise public awareness, rethink humannature relationship, and initiate fundamental changes in our socio-economic behaviors.

\section{AUTHOR CONTRIBUTIONS}

All authors listed have made a substantial, direct and intellectual contribution to the work, and approved it for publication.

\section{ACKNOWLEDGMENTS}

We sincerely thank for the participation and contribution from the authors, the rigorous and constructive reviews from the reviewers and editors, as well as the guidance and assistance from Frontiers in Water staff. This issue could not be possible without their help and support!

Conflict of Interest: The authors declare that the research was conducted in the absence of any commercial or financial relationships that could be construed as a potential conflict of interest.

Copyright (c) $2021 \mathrm{Ma}, \mathrm{Li}$, Shen, Chrysikopoulos and Kim. This is an open-access article distributed under the terms of the Creative Commons Attribution License (CC $B Y)$. The use, distribution or reproduction in other forums is permitted, provided the original author(s) and the copyright owner(s) are credited and that the original publication in this journal is cited, in accordance with accepted academic practice. No use, distribution or reproduction is permitted which does not comply with these terms. 